LA-UR- 09-02868

Approved for public release.

distribution is unlimited.

\author{
Title: \\ Emergency Relocation: Population Response Model to \\ Disasters
}

Intended for:

\author{
Nicolas Hengartner \\ Leticia Cuellar \\ Deborah Kubicek \\ Anders Hansson
}

Publication in the proceedings of 2009 IEEE International Conference on Technologies for Homeland Security

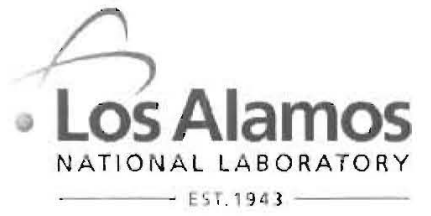

Los Alamos National Laboratory, an affirmatve action/equal oppontunily employer, is operated by the Los Alamos National Security. LLC for the National Nuclear Security Administration of the U.S. Department of Energy under contract DE-AC52-06NA25396. By acceplance of this article. the publisher recognizes that the U.S. Government relains a nonexclusive, royalty-free license to publish or reproduce the published form of this contribution, or to allow others 10 do so, for U.S. Government purposes. Los Alamos National Laboratory requests that the publisher identify this article as work periormed under the auspices of the U.S. Depanment of Energy. Los Alamos National Laboratory strongiy supports academic freedom and a researcher's right to publish; as an institution. however. 1he Laboratory does not endorse the viewpoint of a publication or guarantee its technical correctness

Form $836(7,06)$ 


\section{Emergency Relocation: Population Response Model to Disasters}

\author{
Leticia Cuéllat \\ and Deborah Kubicek \\ Risk Analysis and Decision Application \\ Los Alamos National Laboratory \\ Los Alamos, New Mexico, 87544 \\ Email: \{leticia, kubicek\}@lanl.gov
}

\author{
Nicolas Hengartner \\ Information Sciences \\ Los Alamos National Laboratory \\ Los Alamos, New Mexico, 87544 \\ Email: nickh@lanl.gov \\ Corresponding Author
}

\author{
Anders Hansson \\ Ericsson \\ Goeteborg, Sweden
}

\begin{abstract}
This paper presents a a general framework for applying individual decision models to aggregated populations. Our approach is useful for modeling and predicting evacuation decisions from disasters, ranging from earthquakes, flooding and wild fires, to industrial emergencies like chemical spills or nuclear accidents, to reactions to terrorism attacks. The novelty of our approach is to apply well-documented household evacuation behavioral models to statistical/accurate synthetic populations with detailed demographic information. Predictions of who evacuates and who does not evacuate, and the type and Iocation of the selected shelters is useful for emergency management and planning. We illustrate it by applying our tools to predict emergency relocation behavior from hurricanes.
\end{abstract}

\section{INTRODUCTION}

Hurricanes are a fact of life in the south-east of the USA. While it is possible to prepare to weather them. sometimes it is better to get out of their way. This it is crucial for the population at risk. and the government. 10 plan and juepare for an eventual evacuation.

One of the lessons learned from Hurricane Katrina is the importance of developing contingency plans for mas ive evacuation. Not only does the impacted area need an emergency evacuation plan, but the surounding rural communities and metro areas musi be ready to absorb a large influx of evacuees and be prepared to respond to the increased demands on infrastructure and resources from the evacuees. For example. it is estimated that one million people evacuated greater New Orleans for Katrina, of which as many as 10,000 people, mostly the poor failed to evacuate: at least 150,000 took refuge in Houston, while over 250.000 people evacuated to nearby Baton Rouge. This mass evacuation, jointly with the government's inability to respond fast enough), was in part responsible for the chaos that followed Katrina.

Predictive models forecasting who evacuates an impending hurricane. where they evacuate 10 , and to what lype of shelter. and al:o who stays behind, provide important information for energency management and plannine in many ways. First, knowing where the evacuees are relocating can help allocate resnurce during an ongoing event and inform emergency workers about the population at sisk from a fallure to evacuate in ume. Second prediction of evacuation behavior from hypothetical events allows analusts (o) alssess the robustness of infrastructures from increased demands arising from the influx of evacuees into an area and helps to locate shelters and stockpiles. Third, the relocation predictions, when used as a planning tool, can bring together the stakeholders and government officials that need to work together in the event of a disaster.

This paper presents a science-based approach in predict evacuation and relocation behavior. There are many studies that identify important factors of evacuation decisions. Posthurricane surveys provide detailed insight into the characteristics of individuals and households who chose to evacuate and those who choose to stay. A common feature of all these surveys is that the decision to evacuate is based on the perceived risk of each individual and/or household. Baker [5] studied 12 hunicanes from 1961 to 1989 covering almost every state from Texas to Massachusetts and concludes that the major factors determing the decision to evacuate are risk level of the area, actions of public authorities, housing, storm specific threal factor and prinr perception of personal risk. Models that relate the perceived risk of individuals and households to characteristics and attributes of the individuals and households can predict evacuation behavior for future events. The problem with this approach is that in general, the characteristics for each individual in the population that are needed to make evacuation predictions, are not available. At best, we may know the marginal distribution of each characteristic of interest for the population aggregated at some geographic resolution. such as the census block, the census tract or the county level.

This creates an information gap between the needed and the available information. The contribution of this paper is at new way to bridge this gap through the construction of a statistically accurate population of households endowed with the required characteristics for the model, 10 which the inclividual behavior model can be applicd. A similar idea is used in activity-based transportation modeling where the results of local travel/actvily surveys of individuals need w be transferred to other populations. The latter synthetic population only requires a few (up to four) covariates and is therefore significantly simpler than the synthetic population requred for relocation prediction which requires reguires up 10 twelve atributes. Given a synthetic poputation, statistical prediction 
of the relocation is possible by applying household behavioral models to a population only known at an aggregated level.

We have produced a prototype for a tool that implements these ideas io predict relocation from hurricanes. Our tool takes as input the predicted path and strength of the hurricane at landfall, flooding and wind lisk zones, census data for both the impacted area and its surroundings. and information about location and capacities of public emergency shelters and hotels. The output from the tool, which requires between ten to twenty minutes of computation on a standard desktop computer, consisis of a list of households that evacuate, with the location and type of shelter each household uses, and a list of households that fail to evacuate. The results can easily be tabulated and visually displayed using standard Geographica] Information Systems (GIS). We have tested our models for hurricanes Katrina (August 2005), Gustave (August 2008) and Ike (September 2008). Comparison to the predictions from our tool are good.

The current implementation of our tool is not dynamic, meaning that the outflow of evacuees is nor modeled as a function of time. We assume that anybody that decides to evacuate, provided they have a vehicle, is able to relocate. Many existing macro traffic simulators. like NEVTAC [19], or Evacuation Traffic Information System [17] used by the states of Florida, Georgia, Alabama, North Carolina, and South Carolina, simulate the actual evacuation, but require as input among other factors, the expected evacuation participation rate, and destination percentages for expected counties, although default values are provided. Thus it is possible to extend our tool to produce time dependent answers in the future.

There are many other scenarios beyond huricanes for which evacuation predictions are desirable. For example, such predictions would have been useful during the 1979 Three Miles Island reactor crisis, where between March 28 and April 4 , over 144,000 people evacuated [20], and more recently during the California wildfires in the Fall of 2007, where over half a million residents left their homes to seek shelter. Prediction of evacuation behavior was an important component in the recent terrorism preparedness exercise Top Officials 4 in October 2007, that simulated terorists detonating a radiological dispersion device (RDD) or dirty bomb causing widespread contamination in Portland, Oregon. Phoenix, Arizona, and the U.S. Territory of Guam.

This paper is organized as fellows. Seclion II reviews perceived risk based evacuation behavional models for evacuation and Section IIl discusses how to model shelter type and location. Section IV discusses how to generate a synthetic population of households while Section $V$ presents an overview of the implementation of the tool. An illustrative example is given in Section VI and we conclude the paper in section VII.

\section{MODELING INDIVIDUAL BEHAVIOR}

The literature on evacuation behavior documents that the decision to evacuate generally occurs at the household level [2], 15], [7], [10], [12], and [22]. That is either the entire household evacuates or not. The decision to evacuate depends on the perceived risk that the hurricane poses to the household [1] and [2]. It should be noted that the notion of perceived risk is a recurring theme in evacuation modeling in general. See, for example, the studies by Johnson, $[1+]$ and $[15]$. on the evacuation in the wake of the Three Mile Island nuclear reaciol malfunction. These studies made evident the effect of perceived risk and the resulling shadow evacuation phenomena, i.e., more people than those identified as vulnerable decicled to evacuate

A challenging aspect of perceived risk modeling, is that the evacuation behavior for each humicane is unique, even for hurricanes of the same strength that hit land in the same general area. For example, there are instances of two humicanes that followed one another within a few weeks. Both hurricanes were of comparable strength. However, the evacuation rates for the second hurricane was lower than for the first. Conversely, the evacuation rates for Hurricane Rita, which followed Hurricane Katrina, was much higher than anticipated. Particulars of the hurricane also impact the perceived risk. For example, anecdotal evidence suggests that the speed of the hurricane can impact evacuation behavior. In a recent hurricane, the storm slowed down just before landfall. Since the hurricane did not hit the shores when first anticipated, the population returned, just to be told to evacuate again when the storm stanted to move again. This second evacuation order was ignored by a substantial part of the population.

Nevertheless, post-hurricane surveys and hypothetical hurricane behavioral studies are useful to identify imporant factors that help to predict behavior of households in the event of a hurricane landfall, i.e. the evacuation decision (see for example [7], and [22]). And although there are documented differences between hypothetical and actual evacuation behavior [23], these surveys can help build statistical models, using logistic regression and neural networks (see for example [13], [22], and [24]) that can predict the likelihood of evacuation. The statistical models from the various studies shows a surprising consistency for which factors are imponant to predict evacuation behavior. We take this as evidence that it is possible to model perceived risk from historical and hyporhetical evacuation surveys.

These studies consistently identify housing type and 10cation as important factors ([1],[7], and [12]). Specificaliy, households living in mobile homes or in multiple-unit housing are more likely to evacuate than households living in detached single-family units ([12] and [22]). Also, awareness that the housing unit is located in a flood or evacuation zone increases the probability of evacuation.

Household composition is another important factor: the presence of children in a household makes it more likely to evacuate while the presence of elderly in a household makes it less likely to evacuate [7] and [12]. Health status and pet ownership are also influential factors [12]. Eclucation of the resident. a proxy for social status, is another facior. Interestingly, no study found household income to be a determining 
factor for evacuation. although it affects where household evacuates.

The location of the household is another importani hactos: Households located in known and well-adverised evacuation areas (prone to flooding or high wind risk) are more likely to evacuate. There is an ongoing debate about the impact of tenure, that is, the length of time the household has lived at the same location. One camp argues that tenure increases the chance of evacuation because the household is more familiar with hurricanes and hence better able to asses the risk it poses, while the other camp argues that it decreases the chance of evacuation due to hurricane fatigue (i.e., a sense of hopelessness and frustration from dealing with the stress of multiple huricanes). The data from specific humicanes sometimes support one camp, and sometimes the other.

Finally, government intervention is an important factor. Here, intervention refers to various sorts of announcements, from broadcasting to door-fo-door notification. The probability of evacuation depends on how well the household is informed by the government. In the modeling effort. English/Spanish proficiency was considered, or rather the lack of it, as a barier to receiving the evacuation order:

\section{MODEling SHELTER TYPE AND GEO-LOCATIOIN}

Historical data from past hurricanes indicate that typically, between $45 \%$ to $70 \%$ of the evacuated households stay with friends and family, and that between $20 \%$ to $40 \%$ of the evacuees go to hotels and motels. The remaining $5 \%$ and $25 \%$ go to public shelters. The actual percentage depends on demographics. hurricane strength, population density of the evacuated area, and population density of the neighboring communities. As a rule of thumb, shelcers are always underutilized. The only known exception to this rule is during a catastrophic event that affects the households that did not evacuate in time. In that case. the population will potentially seek and hil up the shelters of last resort to capacity. The fooding of New Orleans in the wake of Hurricane Kauna is an example of this.

In a comprehensive siudy [22]. Whitehead us a multiplechoice model to deternine what factors impact the choice of shelter. Some of the factors identied were hurricane characteristics, income. houscholder's race, sex and education, and housing type. As for the decision to evacuale. there is strong hurricane-to-hurricane variability, based on the data from the post-hurricane studies commissioned by the U.S. Army Corps of Engineers ([2], [3], and [4])

There are a limired number of studies on distance traveled when evacuating 191 . Given the guidelincs of posthurricane studies [1] a gratvily model was cho:in (in which the atractiveness of a shelter increases with the number of evacuees it can harbor. but (leclines with increasing distance). A recent Ph.D. thesis proposes an economics based approach 17j. Thus is an intriguing idea. This idea is partially adopted by considering a different gravity model for each shelter type. In the implementation of the gravity. a hard linut on the hotel/motel and public sheler calicities was enforced. This forces mdividuals who choose these shelter lypes (o) move further away from the evacuation area in scarch of shclier.

\section{SYNTHETIC POPLLATION TO BRIDGE THE DATA GAP}

The perceived risk models require knowledge of sociodemographic attributes for each individual is predict evacuation behavior. Unfortunately, the population at risk is rarely known al that level of detail. Instead, the characteristics of the population are usually only known at an aggregated level, such as in a census block. census tract or councy. Furthesmore. one often only knows the marginal distribution - the distribution of one characterisic at the time - of each characteristic of interest within each geographic region.

To circumvent this aggregation problem and allow us to apply the individual perceived risk model, we propose to create a statistically representative synthetic population. The individuals of that population are endowed with the charateristics required by the risk based models, and the synthetic population is constructed in such a way that the marginal distributions of the various characteristics match the marginal distribution observed in the aggregated population. Note that if the whole population is composed of several aggregated subpopulations (think of a county being composed of several census blockgroups), then we may wish to generate a synthetic population for each of the subpopulation.

The idea is to estimate the individual probability of evacuating using demographics, the hurricane's characteristics and information about government intervention, and then aggregate the results for the entire population. In this manner the results are based on predictions of individual behavior, that will vary according to the population's composition, and are guarantec 4 to be reliable estimates by the low of large numbers. Thus, having a synthetic population that is statistically equivalent to the census, allows to do forecast in real time and for hypothetical scenarios.

We apply the methodology developped by Beckman ef al. [6] in the context of activity based transportution modeling, to construct a statistically accurate synthetic population of households with demographic characteristics that closely match the population under study. The methodology applies an iterative proportional fitting algorithm (0) the Public-Use Microdaca Samples (PUMS) data in a way that matches the following marginals provided in the Summary Files 3 (SF3 from the 2000 Census) at the block group level. For each synthetic household, the following variables are extracted from the PUMS and matched to the marginal distribuion in each census block-group:

- Gender of househola ouner (Male/Fenale)

- Race/ethnicily of houschold (White/Black/Hispanic/Other)

- Household income (in Jullars)

- Sizc of household

- Housing type (single unit, multi-unit, mobile home)

- Numher of available vehicles

- Presence of childien (18 years and younger) in household

- Presence of elderly (65 years and ndder) in household 
- Presence of malivit....l: in housenold with various disabilitics

- Number of years of education of household owner.

This produces a synthetic population of households with the demographic characterisitcs described for each census block group. If needed. these households can be geo-located within each census block group, but for this particular application, the census block group provides a reasonable level of resolution given that lypically evacuation orders are given at the county level.

We note that a major difference between our synthetic population. and the synthetic populations used by the transportation community, is the number of factors on each individual we attempt to match.

\section{IMPLEMENTATION}

Figure 1 shows the overall flow diagram of the hurricane relocation tool that computes statistically accurate reallocation status (evacuate or not) for each household in the impacted area. For households that evacuate, our tool determines the type of shelter and its location. The resulting information is readily summarized into the number of individuals who neglect to evacuate in each impacted census block group and the number of evacuees relocating to friends and family, hotels and motels, and public shelters for each of the block groups and counties that receive any evacuees. The results are subsequently analyzed and visualized using a GIS software. An example is provided in Section VI

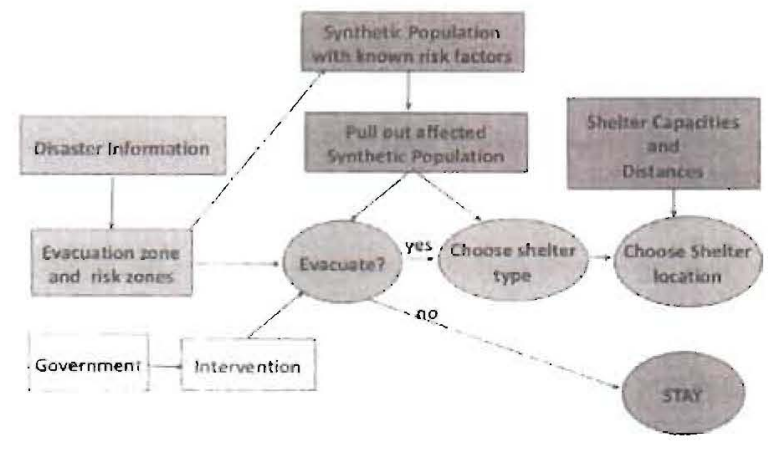

Fig I Flow chart of the hurricane relocation rool

The model consists of two main components, the synthetic population generator previously discussed and the evacuation behavior model that we detail in Section V-B. Section V-A describes the input data requirements, and section $\mathrm{V}-\mathrm{C}$ discusses some added features of the model.

\section{A. Data requirement}

The model requires the following input data:

- Predicted hurricane characteristics. This is usually given in the form of a map that shows the likely region for the huricane landfall logether with high wind and fooding risk zones further inland. Currently. we only use information about the flooding level, but information about high wind risk zones will be incorportated. In addition. the model requires an estimate of the hurricane strength (in the Saffir-Simpson scale) at landfall.

- Geographical Information System map of census block groups (a census block group is the smatlest geographic unit used by the U.S. Census Bureau for tabulation of 100-percent data, i.e., data collected from all households, rather than a sample of houses). These maps are used to determine which census block groups are in the likely path of the hurricane and will be required to evacuate.

- Population demographics at the census block group level. This data describes the marginal distribution of demographic variables.

- Public-Use Microdata Samples (PUMS), 5\% sample for the region under study. This data is used 10 create synthetic households that statistically match the marginal characteristics from the census in each blockgroup.

- Risk zones for flooding or evacuation zones. Ideally, this data is provided in the form of Shapefiles (i.e., geospatial vector data for geographic information systems software, developed and regulated by ESRI) registered with the census block group map.

- Capacity Information. Number of schools and enrollment in each census block group, together with the number of churches together with the number of church employees, are used to determine the capacity of public shelters. The number of hotel and motel beds in each block group is inferred from the Dun \& Bradstreet database.

\section{B. Evacuation behavior}

The evacuation behavior model consists of three modules that takes as input the households from the synthetic population to simulate the evacuation decision based on the perceived risks of that household, and if needed, the selection and geolocation of the shelter.

1) Evacuation Decision Module: The implemented module is illustrated in Figure 2. The basic structure for the decision to evacuate is to compute a perceived risk factor, modulated by the effectiveness of government interventions. If a decision to evacuate is made, the ability of that household to execute its decision is evaluated based on the availability of a vehicle.

The perceived risk model is an adaptation of the logistic model for the probability of evacuation reported in [22]. The model is an adaptation since some of the variables in the original model are not available. Whenever possible, the missing variables were marginalized and the intercepts were adjusted accordingly.

Whitehead's model [22] was slightly modified by treating the presence of disabled individuals in the household as the presence of an additional elderly individual. This is to account for health status of the members of the household, which Heath et al. have found to be significant [12]. 


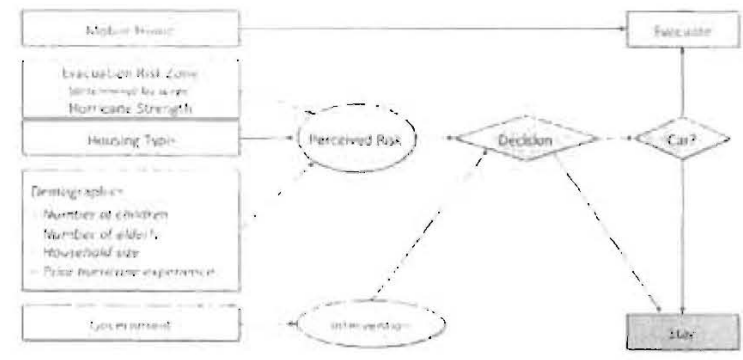

Fig 2. Evacuation Decision.- Schematic illustration of the logistic model for a synthetic household: decision to evacuate.

Heath et al. also found pet ownership to be an important factor for houstholds deciding to evacuate [12]. Given that 1) none of the accessible data sources help to determine pet ownership, and 2) pet ownership is likely to be ubiquitous (that is, farly uniformly distributed over the entire population), this factor is treated as missing, and the intercept of the logistic model is adjusied.

Finally, our model adopts a blanket rule that all households living in mobile homes located within the evacuation zone (see section V-C) evacuate. This is consistent with the literature, which repeatedly identifics mobile homes as the most vulnerable type of housing units to high winds

The role of government intervention is to convince more people to evacuate. The underiying premise is that the population understands such order. An assumption is that this order is likely to be given in both English and Spanish. However, it is possible that households that are not proficient in English/Spanish will not understand the order and neglect to evacuate. This resulted in a small enough change in the original government intervention variable such that the coefficient of that variable did not need to be adjusted.

2) Sheller-Type Decision Module: Figure 3 shows the flow diagram for the shelter-type decision module. Most reports classify shelter types into three categories: 1) emergency or public shelters, 2) hotels and motels, and 3) friends and family. Beyond these three types, a few studies consider mobile homes and tranlers as viable shcliters. In practice. these make up only a small fraction of shelters (less than 6\%).

Whitebead ct al. consider a multiple-choice model for the decision of the type of shelter [22]. As for the decision to evacuate. a few of the variables in the model are missing, namely pets and wind risk (which will be incorportated in a later version). The module solves this problem by averaging over the marginal clistribution of the missing covariate and suitably adjusting the mercept.
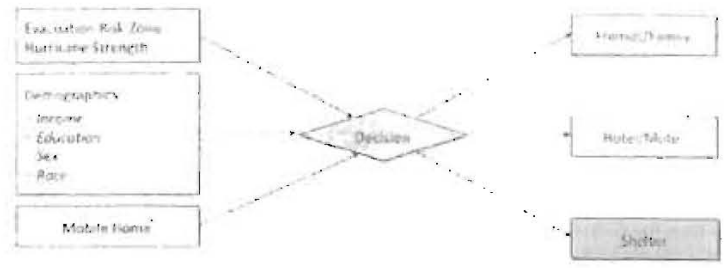

Fig. 3. Shelter-1ype Decision.- Schematic illustration of the mulitplc-choice model for a synthetic household's choice of shelter type (given the houschold evacuates)

In Whitehead's model, households that belong to the region's dominant racial group are more likely 10 stay with family/friends [22]. Since the study was conducted for a racially homogenous region, the model was adjusted so that households that belong to any of the region's two dominant racial groups are more likely to stay with family/friends.

3) Shelter Geo-location Moclule: The decision about where to evacuate depends on the shelic type, and this enables the shelter geo-location module to indirectly incorporate socioeconomic considerations. The guidelines for huricane studies, see [1] and [10], suggests that the simplest model is to allocate the evacuees proportionally to the population of the possible region where they evacuate to, possible weighted by a function of distance. " This is essentially a gravily model that has successfully been used by TRANSIMS [21] and Dow [9].

The gravity model used here was built based on a general understanding of how people evacuate. For example, for friends and family, the module used race affinity to determine the size of the attractors. That is, evacuees are more likely 10 stay with someone from the same racial make-up as the head of household. For hotels/motels, the module incorporates an attrictor by estimating the number of vacant rooms as measured by the number of employees and assumes (based on hotel occupancy data) that the hotels were at $40 \%$ capacity before the hurricane. For the emergency shelters, the module uses schools (in accordance with Red Cross and local contingency plans), determining the size of the shelter by assuming that a school will less than 1,000 students has the cquivilent of one gymnasium (which holds 50 people) and that at school with more than 1,000 students has the equivalent of two gymasta (holding a total of 100 people). Shelters of lalst resort. such as coliseums. are included only under mandatoly evacuations orders, and if any knowledge about the utilization of such shelters is available. Recall, however, that oul tool estimates the number of people/households failing to evacuate. In cases of catastrophic events, these people are furced to seek local 
refuge in shelters of last resont. Thus. the model gives a bound on the required capacity for shelters of last resort.

The module assumes that in the event of a large storm. evacuees will be willing to travel farther than m the event of a weaker storm. This was modeled by weighting the distance with the Saffir-Simpson hurricane strength. We implemem this idea by dividing the entire region into evacuation bands. At the onset of the simulation. we let individuals go to the nearest band, but as the number of evacuees in the first band approaches its capacity, we let the evacuees move to the next band. This approach is computationally more efficient than than randomly selecting the shelter location and rejecting the selection if it is over capacity

\section{Practical considerations}

From a probable hurricane path, we can identify the areas (and hence the population) impacted by the storm. To reflect differential impact of storm surges and high winds to different regions within the landfall, we divide the region into risk zones that have, or are perceived to have, comparable risk. Ideally these areas should be determined by local management agencies, and their levels should conespond to what most local manacement agencies define as the different evacuation zoncs In the bsence of reliable local information, one can construct risk zones from huricane surge maps, possibly combining multiple landfall scenarios. Table I details our choice of risk zones as a function of maximal flooding level from multiple scenarios.

TABLE I

RISK LEVELS ACCORDING TO EXPECTED SURGE.

\begin{tabular}{|c|c|}
\hline Flooding level in feet & Risk level \\
\hline 0 & 0 \\
$(0.5]$ & 1 \\
$(5,8]$ & 2 \\
$(8.12)$ & 3 \\
$(12,18]$ & 4 \\
more than 18 & 5 \\
\hline
\end{tabular}

There are several ways to resolve a mismatch between the risk zone and census boundaries. We choose to use the most conservative approach, labeling entire census block-group with the highest risk level it contains. We argue that this choice accounts for "herd behavior". where the evacuation from a neighbor can increase ones perceived risk, and lead to an sympathetic evacuation.

\section{Limitations of the curreni inodel}

Like all models, ours has several limultions. For one, it does not consider transient populations such as vacationers. The evacuation study guidelines |I| mention this part of the population, but note that in the event of a hurricane, they are likely to evacuat: early and return home. As a result, transient populations have been excluded because they will not significantly add to the demands on infrastructure and resources in the neighboring communities.

Another limitation is that the model is not dynamic the suthow of people is not modeled as a function of time, and how that outflow is influenced by the clanging nuture of the storm. Congestion is not modeled either, which assumes that everyone who wants to evacuate can, provided they have a vehicle available to do so, unless mandatory evicuation orders are issued, in which case we assume that the goverment will make means of trasportation available for all those who don it own a car and decide to evacuate. The current implementation randomizes the order for the decision of carch household to evacuate

\section{EXAMPLE}

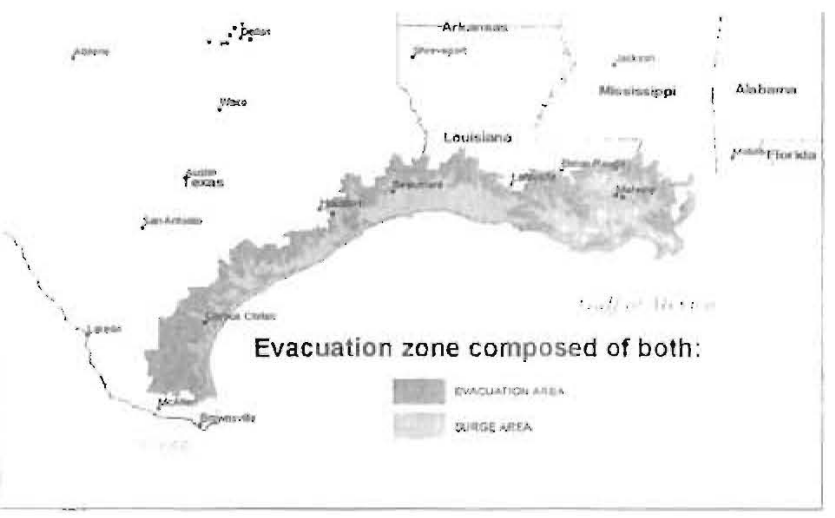

Fig. 4. Surge maps and associated evacuallion zone predicted for Hurricane lke. Evacuations were recommended or mandated along the entire Golf coast of Texas. Louisiana and part of Mississippi. The eye of the hurricane made landfall near Husion. TX.

As an illustrative example, consider the problem of predicling evacuation and relocation patterns from hurricane Ike which made landfall over Galveston Island. Texas on Saturday September 13th. Ike was predicted to make landfall as a category four hurricane on the Saftir-Simpson-Scale, but weakened to a category two hurricane by the time it reach land. Just a few days earlier lke was expected to be the deadliest hurricanes in U.S. history, and do tremendous damage given its enormous size with winds hurricane force extending outward up to 120 miles from the center, and tropical storm force winds up to 275 miles. Ike ended up losing strength and did not reach the predicted level. While the top wind-speeds at landfall (around 110 miles per hour) was less than initially predicted, the accompanying flood surges were characteristic of a category four hurricane. This anecdotal evidence points to the robustness of our tool to make predictions, even if the characteristics of the hurricane change between the tine the prediction is made and the time landfall occurs.

The predictions we produced from out tool are based on advisory 45 from the National Oceanic and Amospleric Administrations (NOAA's) National Hurricane Center. In that advisory report, Ike was predicled to produce fiond surges from just north of Brownsville, $T X$ and covering the rest of the Texan and Louisianan coastlines. and touching the cost of Mississippi. We constructed the pracuation zone by selecting all the blockgroups that intersect the surge area, and subsequently adding all those blockgroups that are adjacent in 
the lirst set of blocknoups (Ficure 4). The flood surge was computed assuming a category three hurricine would makc lindfall a reasonable assumption at that time.

Assuming a mandatory evacuation was in effect for the entire flood zone. our tool predicted 700,000 evacuces from Louisiand, and 880,000 trom Texas for a total of 1.6 inillion evacuees. The region impacied by an actual evacuation orders differed from what we used in our simulations. And while the actual evacuation zone included areas along the coastline, it also included in some instances whole countics. Nevertheless, the predictions from the tool are close to the official reported evacuation numbers of around eight hundred thousand evacuees from Louisiana, and somewhat larger than the reported one million evacuees from Texas.

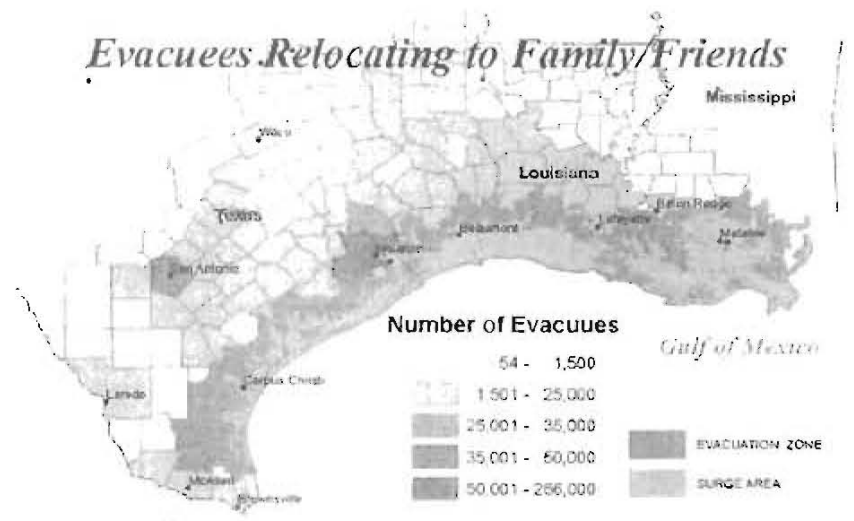

Fig. 5. Predicted relocation of evacuees from Hurricane the to friends and family. Evacuees to friends and family shelters travel more on average than evacuecs, that relocate with public shelters or hotels and motels.

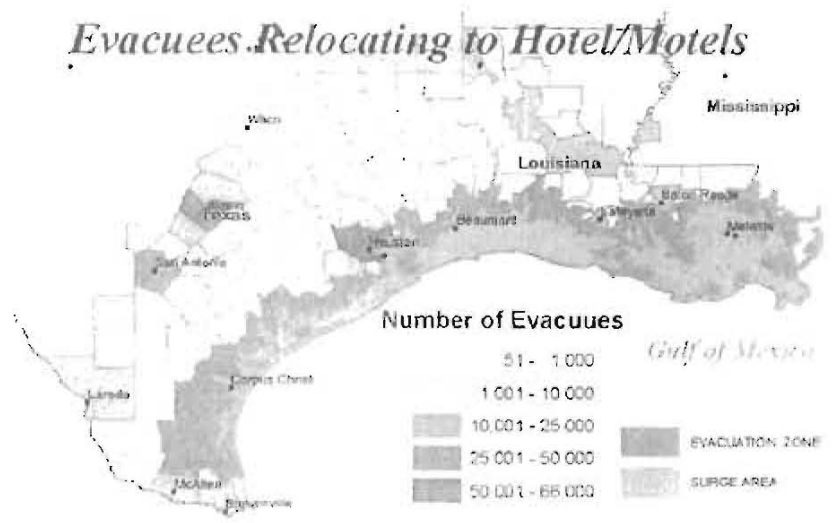

Fig. 6. Predicted relocation of evacuces from Hurricane the 10 hotels and motels.

Figures 5 - 7 show where people choose to rclocate. Notc that people sheltering with friend and family travel the largest distance, while people going to hotels tend to go to bigges cities. and evacuees taking refuge in public shelters travel the least distance.

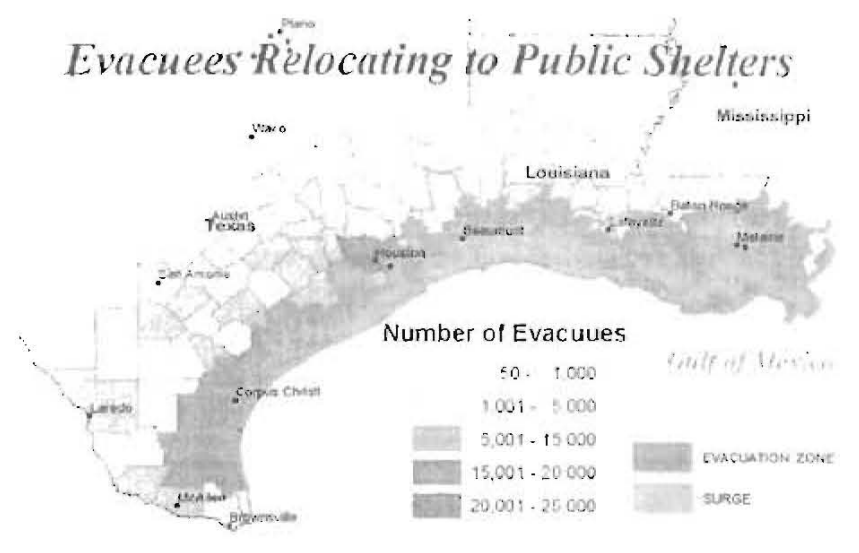

Fig. 7. Predicted relocation of evacuees from Huricane lke to public shelters. Evacuees 10 public emergency shelters travel less: on average than evacuees that relocate with friends and family or to hotels and motels.

\section{CONCLUSION}

This paper presents a paradigm for predicting the evacuation and relocation behavior of a population in a wake of a hurricane. Given a hurricane scenario, the model estimates the total number of houselolds evacuating using a logistic model, their choice of shelter type using a mulii-choice model, and finally where the household will relocate via a weigthed gravity model. The aggregated results: total number of evacuess, total number of people choosing different types of shelter, and the total amoun of people relocating to other communities provide statistically significant estimates to decision makeis.

\section{ACKNOWLEDGMENT}

This work was funded in part by the National Infrastructure Simulation and Analysis Center funded by bopartment of Homeland Security.

\section{REFERENCI:S}

[1] Technical Guidelines for Huricane Evacuation Studies, U.S. Arriy Corps of Enginec... 19\%5.

[2] South Carolina Hurricane F:valcuation Sudy. Behavioral Analysic. Hazards M.1 agement Croup. Inc.. 1986.

[3] Alabarna Hurricane Evacuanon Sludy. U.S. Army Corps of Enginters. 2001

[4] Georgia Hurricane Evacuation Study. U.S. Amy Cons of Engineers. 2002 .

(5) Baker. E.J. (1991). Hurricane evacuation behavior. International Journal of Mass Emergencies and Disasicrs. 9(2). pp 287-310.

[6] Beckman, R.J., Baggerly. K.A.. McKay. M.D. (1996). Creating Synthetic Baseline Populations. Transportation Research. Parl A. Policy and Pracice.30(6). pp $\$ 15.129$.

< hitp://ndssi ubivitedis/Pabicatrons/Transimsvolb pdf >

(7) Dash. $N$ and Gladwm. H(2005), "Evacuation decision making and behavioral responses: Individual ind household." Manuscript prepared for the Hurricane Forccans Socincconomic Workshop. February if 18. Pomona. CA.

(8) Dombroski. M.. Fischhoff. B. and Fischbeck. P. (2006). "Predicing cmerency evacuation and sheleng behavior: A structural analyucal approach". Risk Analysis. 26. No 6. pp 1675.1688.

[9] Dow. Kand Cutler. S. L. (2202), "Emerging hurricane evacuaton ussues: Hurricane Floyd and South Carolina." Natural Hazands Review. 3. pp $12-18$

|10) Drabek. T. E. and Boges, K S (19681. "Fandilies in dikaster Reaction and veldtives." Joumal of Matriage and the Fanily. 30, pp. 443.451 , 
111) Fu. H. (2004). "Development of dyname trivel demand models for hurricane evacuation". Ph.D. Thesis. Department of Civil and Enviromemal engineering. Lomisana State Universily. LA

[12] Healh, S E. Kais: P. H. Beck A. M. and Glickman. L. T.(20)1\}). "Human and pet-telated lisk factors for household evacuation failure during a naturib disister." American Journal of Epidemiology. 153. pp. 659-665.

[13] Irwin. M. D. and Hurbert J S. (1995). "A behavioral analysis ol hurricanc prepardnes: and evacuation in southwestern Louisiana". Louisiana Population Data Center. Louisiana State University. Baton Rour. LA.

[1-] Johnson. J. H.(1985). "A node] of evacuation-decision nxaking in ? nuclear reaclor emergency." Geographical Review. 75. pp. $40.5+418$.

[15] Johnson, 1, Zeigler. D) (1986). "Modeling cvacuation behavior during the Three Mile Island reactor crisis". Socio-Econ. Plan. Sci. 20. No. 3. pp $165-171$.

[16] Mei, B.(2002) "Development of trip genesation models of hurricane evacuation". Master thesis, Lousiana Statc University. Baton Rouge. LA

[17] Post. Buckley. Schuh \& Jemigan. Inc. (2000). "Southeast United States Hurricane Evacuation Traffic Study: Behavional analysis. Technical Memorandum 1". Final Report. Tallahassee. FL, May 2000

[18] Regional Deparment Service. Department of Sociology, and Deparment of Economics (1999) "Executive sumnlary of a socioeconomic hurricane impaci analysis and a hurricane evacuation impact assessment 100 l (methodology) for Coastal North Carolina: A case study of hurricane Bonnie". Easr carolina Universits: Greenville. NC.

[19] Sheff, Y. Mahmassam. H., and Yowell, W. B. (1982). "Transportation network evacuation model", Transportation Reaserach $16 \mathrm{~A}$ ㅇ.3, pp 209.218.

[20] Stallings, R. A (1884) "Evacuation behavior at Three Miles Island" International Journal of Mass Emergencies and Disasters.

[2I] Barrell, C. L.. Beckman, R. J.. Berkbigler, K. P., Bisset, K. R. Bush, B. W., Eubank. S. Henson. K. M. Hurford, J. M., Kubicek, D. A., Marathe, M. V. Romero. P. R. Smith, J. P.. Smith. L. L.. Speckman, P. L., Stretz, P. E., Thaver, G. L.. Van Eeckhout, E., Williams, M. D. (2004), "TRANSIMS." Technical Report LA-UR 00-1725 \& 00-1767, Los Alamos National Laboratory. Los Alamos, NM.

[22] Whitehead, J. C.. Edwards, B.. Van Willigen. M. Maiolo. J. R., Wilson, K., and Smith. K. T. (2000). "Heading for higher ground: Factors affecting real and hypothetical hurricane evacuation behavior". Global Environmental Change Pat B: Environmental Hazards. 2. pp. 133-142.

[23] Whitehead, J.C. (2005). "Environmental risk and averting betiavior: Predictive validity of jointly estimated revealed and stated behavior data". Environmental \&: Resources Economics, 32 pp-301-316.

[24] Wilmot. C.G. and Mei, B. (2004). "Comparison of Alternative Trip Generation Models for Hurricane Evacuacion ". Natural Hazards Review, 5. No.4. pp 170-178.

[25] H. Kopka and P. W. Daly. A Guide w $b T_{E} X$. 3rd ed. Harlow. England: Addison-Wesley. 1999. 